\title{
SOBERANIA NACIONAL E AUTODETERMINAÇÃO DOS POVOS
}

Em 1999, proferi palestra, na Escola Superior de Guerra, sobre limites da soberania em sua nova concepção jurídica e geo-política.

Resolvi transformar em artigo as idéias lá expostas, considerando que, pela abrangência da temática que a "Revista Acadêmica" comporta, uma reflexão maior sobre a matéria seria justificável, mormente pelos estudantes universitários, que deverão, no futuro, enfrentar as vertentes que se vislumbram, na convivência internacional, sobre os sistemas jurídicos dominantes na atualidade.

Tema, que volta à baila em decorrência dos tratados internacionais que o país vem assinando, reside nos pontos que podem afetar a soberania nacional, em face de eventual perda de controle do princípio da razoabilidade por parte dos órgãos que cuidam da prevalência dos tratados sobre o direito interno.

Três grandes vertentes de pensamento dominam, atualmente, as reflexões sobre o direito internacional, a primeira delas entendendo deva esta prevalecer sobre o direito interno; a segunda, que a soberania das nações relativisou-se perante o direito internacional; e a terceira, que os princípios de direito natural, expressos na declaração universal dos direitos fundamentais, prevalecem sobre o direito internacional, comunitário ou interno. ${ }^{1}$

A discussão acadêmica, todavia, perde espaço para uma realidade em que as grandes nações continuam impondo seus estilos e sua força às nações mais fracas, inclusive por incursões bélicas, permitindo-se, todavia, não respeitar tais princípios internamente.

Em outras palavras, são mais especializadas em exigir o dever de casa dos outros povos, que cumprir tal dever em sua própria casa.

Há realidades inequívocas de fortalecimento do direito internacional público, principalmente nos espaços comunitários (EU, NAFTA, Mercosul, pacto do Caribe etc.), realçando-se a União Européia, hoje mais uma Federação de países, que uma Confederação, na medida em que o Parlamento Europeu, o Tribunal de Luxemburgo e para 11 países, o Banco Central Europeu, têm mais força que as Casas Congressuais, os Tribunais e os próprios Bancos Centrais internos, nos assuntos comunitários. ${ }^{2}$

É evidente que o fantástico avanço da União Européia, nos últimos 40 anos, visto que o Tratado de Roma é da década de 50, não eliminou as preocupações que ainda permanecem sobre o futuro da comunidade. A estabilidade monetária, para o fortalecimento do Euro, impõe rígida política orçamentária em cada país que adotou a moeda, não podendo ultrapassar 3\% de "déficit público" no conceito nominal, isto é, naquele em que as próprias variações monetárias e cambiais integram-se, nada ficando de fora entre receitas e despesas. Ora, quaisquer desequilíbrios provocados nas economias dos

${ }^{1}$ Celso Bastos, todavia, continua a defender a tese da soberania ampla: "A ordem internacional reinante repousa ainda sobre o conceito da soberania do Estado. Embora a interdependência crescente entre os Estados acabe por diminuir a efetiva capacidade de autodeterminação, não há dúvida, contudo, que os Estados preservam a ilimitação do seu poder, impedindo a formação de uma ordem jurídica internacional cogente que viesse a lhes trazer uma efetiva limitação nas suas possibilidades de ação autônoma. Mesmo os laços mantidos com organismos internacionais não são de molde a retirar dos Estados este papel de protagonistas por excelência da cena internacional". (Comentários à Constituição do Brasil, 1 @o volume, Ed. Saraiva, 1998, p. 454,455).

${ }^{2}$ Sobre o Mercosul, Maria Tereza Cárcomo Lobo ensina: "O tratado do Mercosul foi considerado pelos Estados contratantes

*Professor Emérito das Universidades Mackenzie, Paulista e Escola de Comando e Estado Maior do Exército. Presidente do Conselho de Estudos Jurídicos da Federação do Comércio do Estado de São Paulo e do Centro de Extensão Universitária - CEU. 
países signatários, principalmente na economia dos menores em face de uma crise global, nada obstante o mecanismo de assistência e intervenção adotados, poderiam provocar reflexos nos outros países, já que a moeda não pertencerá a este ou aquele país, mas à comunidade européia, devendo-se transformar, no próximo século, não apenas em moeda escritural, mas de livre circulação.

O robustecimento do direito comunitário decorre, todavia, do fenômeno da globalização, que torna cada vez mais as economias interdependentes, porém as economias mais fracas, mais dependentes das mais fortes. ${ }^{3}$

É interessante notar que os países mais desenvolvidos não permitem que, em suas deliberações (o G-7), os países menos desenvolvidos participem, valendo, as linhas gerais que estabelecem para o mundo, como uma imposição dos mais fortes, que se negam a ouvir as sugestões dos mais fracos.

À evidência, os países mais desenvolvidos continuam a controlar os mecanismos econômi$\cos$ e a intervir, sempre que entendam necessário, na soberania das outras nações, sem respeito maior ao direito internacional público, enquanto reflexo do princípio da autodeterminação dos povos.

A guerra contra o Iraque, a guerra de Kosovo, embora justificadas do ponto de vista ético (defesa do Kuwait invadido e da etnia albanesa), pois em ambos os casos houve violações, por parte de Hussein e Milosevic, de direitos soberanos e fundamentais do ser humano, não escondem interesses outros que não apenas aqueles de imposição das regras dos mais fortes na convivência entre os povos. Os Estados Unidos e seus parceiros mais desenvolvidos não intervieram no massacre da população portuguesa de Timor, pois lá os interesses econômicos são menores, muito embora o custo operacional de uma intervenção seria também muito menor que os "spielberguianos" ataques aéreos à Iugoslávia. Da mesma forma, a nação curda tem sido dizimada pelos tuircos e iraquianos, com um conivente silêncio das nações mais desenvolvidas, em clara demonstração de que o "verniz ético" apenas cobre os interesses de predomínio

como um novo avanço no esforço tendente ao desenvolvimento progressivo de integração da América Latina, revestindo a particularidade de ter fixado, previamente, um período de preparação para o estabelecimento do mercado comum, sua finalidade precípua, situando-o em 31 de dezembro de 1994.

Durante o período de transição, o conjunto institucional do Mercosul era constituído pelo Conselho do mercado Comum e pelo Grupo Mercado Comum. O primeiro, com funções essencialmente políticas, tanto na definição dos princípios informadores do processo de integração quanto na tomada das decisões que o conformam. O segundo como órgão fundamentalmente executivo das regras traçadas.

Em cumprimento do disposto no art. 18 do Tratado de Assunção, em 17 de dezembro de 1994, foi assinado na cidade de Ouro Preto o Protocolo Adicional ao Tratado de Assunção, que dispôs sobre a estrutura institucional definitiva dos órgãos de administração do Mercosul.

No Brasil, o Protocolo de Ouro Preto foi aprovado pelo Decreto Legislativo no 188, de 15 de dezembro de 1995, o Instrumento de Ratificação foi depositado em 16 de fevereiro desse ano e a promulgação ocorreu em 9 de maio de 1996 pelo Decreto n⿳⺈ 1901". (Ordenamento Jurídico Comunitário, Livraria Del Rey Editora, Belo Horizonte, 1997, p.99-100).

${ }^{3}$ Escrevi: "Vive o mundo inteiro uma ilusão, qual seja a de que o endividamento público tem lastro suficiente para suportar todos os investimentos privados, principalmente os financeiros. Nesta ilusão, lastreia-se a estabilidade do sistema financeiro mundial e a capacidade de os governos continuarem a retirar poupança popular para financiar suas despesas, gastando recursos em atividades produtivas e não produtivas, principalmente no que diz respeito à manutenção de sua máquina burocrática, que cresceu assustadoramente, em todos os países, na segunda metade do século, confirmando a validade do pensamento de Adolf Wagner, de que as despesas públicas tendem sempre a crescer e nunca a diminuir.

Os Estados Unidos têm uma dívida pública em torno de 2/3 do PIB, a Itália de 100\%, a Irlanda de 150\%, o Brasil de 50\%, dívida esta sem lastro real, o que vale dizer, seu lastro é a confiança dos investidores de que o governo não dará um calote público, apesar de as evidências demonstrarem que os governos têm dívidas incomensuravelmente superiores às suas forças econômicas. 
das nações mais civilizadas, quando seus próprios interesses estão em jogo. ${ }^{4}$

Prova inequívoca está no protecionismo econômico da União Européia para com sua onerosa produção agropecuária, impedindo a entrada de produtos latino-americanos em condições de competitividade maior, o que vale dizer, para efeito de produtos agropecuários, a União Européia adota a criticadíssima teoria do protecionismo mais antiquado, mais absurdo, mais condenável, em tempos de globalização. Defende, todavia, a aberta globalização para seus produtos industrializados, que invadem a América Latina e os países menos desenvolvidos, à luz do livre comércio, com sucessivas incursões à $\mathrm{OMC}$, protestando contra medidas protecionistas dos países emergentes, sempre que busquem estes assegurar um mínimo de capacitação industrial perante os produtos estrangeiros.

Por outro lado, os Estados Unidos não só não admitem que os tratados internacionais prevaleçam sobre o direito interno, como através dos "countervailing duties", ou seja, das sobre- taxas sobre produtos importados, decidem por conta própria que setores internos devem ser protegidos, alegando a existência de subsídios quanto aos produtos importados. Exercem um protecionismo tão condenável quanto o europeu, em relação aos produtos agropecuários.

É de se lembrar que as grandes sessões do GATT, no passado, e da OMC, no presente, foram e são convocadas sempre pelos Estados Unidos ou por países desenvolvidos, tendo firmado regras teoricamente consensuais - os países emergentes apenas subscreveram os acordos elaborados pelos países desenvolvidos - as quais, à evidência, beneficiam a melhor tecnologia e a maior quantidade de capitais dos países desenvolvidos em relação aos emergentes.

É de se lembrar que autores como Roberto Campos, indiscutivelmente uma das mais brilhantes inteligências do Brasil neste século, chegam a defender a tese de que os países emergentes, na globalização, devem assegurar "nichos de desenvolvimento" em áreas em que estariam mais habilitados que os desenvolvidos, pela

Ocorre que todas as tentativas, no mundo inteiro, de os países, desenvolvidos ou não, reduzirem seus "déficits" revelam-se desalentadoras, continuando a dívida pública mundial a crescer. Cresce também a sua falta de lastro, com o que, apenas por uma profissão de fé, o mundo gira com papéis lastreados em outros sem lastros de todos os governos.

Todos os operadores conhecem esta realidade, mas, como trabalhar com dinheiro de terceiros é fundamental, urge que demonstrem fé no sistema financeiro internacional, capaz de manter sua estabilidade, apesar da absoluta falta de estabilidade dos focos de tensão, que são os perfis da dívida interna e externa de cada país.

Haverá, todavia, um momento em que a manutenção do "déficit" público, financiado pelas aplicações em todo o mundo, não poderá ser mantida, não por força do sistema atual que torna esta realidade apenas conhecida dos que com ela operam, mas por força do conhecimento crescente dos investidores - e não só dos operadores - do real perfil de sua poupança, que só existe porque todos acreditam que os Estados são éticos e respeitáveis e honrarão sempre sua dívida.

Estou convencido de que, no momento em que uma das grandes nações do grupo dos 7 tiver um descontrole capaz de abalar as finanças de inúmeros países mais vinculados, o efeito poderá ser tão grande quanto o da "ilusão das bolsas" em 1929 , nos Estados Unidos.

Quanto mais examino as teorias econômicas modernas - todas procurando saídas marginais para evitar o problema do enfrentamento do descontrole dos "déficits" públicos - mais eu me convenço de que servem elas apenas para anestesiar a capacidade de raciocínio dos que tratam com os valores de investimento do mundo ocidental, até porque tais recursos giram à luz desse sistema deslastreado.

Estou, também, cónvencido de que a estabilidade para atividade econômica sadia, com investimentos não ilusórios, apenas seria possível, se todas as nações controlassem seus "déficits" públicos, mas, por ser utópica tal pretensão, a Economia continuará evoluindo e progredindo até o desastre, pois seu lastro maior de investimento não existe. A economia da ilusão gera uma euforia cujo preço maior ainda está por ser pago". (Uma visão do mundo contemporâneo, Ed. Pioneira, 1996, p. 91-92).

${ }^{4} \mathrm{O}$ artigo 4ำ da Constituição Brasileira tem a seguinte dicção:

"A República Federativa do Brasil rege-se nas suas relações internacionais pelos seguintes princípios:

I. independência nacional;

II. prevalência dos direitos humanos;

III. autodeterminação dos povos; 
impossibilidade de concorrência nos grandes segmentos econômicos. ${ }^{5}$

Em direito internacional, o jurista estuda as regras e as examina como foram postas, mas cabe ao filósofo, ao sociólogo, ao economista e ao humanista perceber as grandes linhas que o conformam. Sempre houve um direito internacional, tendo sido, talvez, os romanos com o "jus gentium”, os que ofertaram a regulação que veio a ser amplificada no mundo moderno. A característica fundamental sempre foi a do predomínio dos mais fortes. Na ONU, com seu Conselho de Segurança - em que algumas nações são privilegiadas em relação a outras - basta o veto de um único desses países para impedir qualquer decisão. ${ }^{6}$

Com toda a evolução semântica dos textos internacionais, com todo o fortalecimento dos direitos comunitários, com toda a massificação da mídia sobre a importância da integração dos povos através dos organismos plurinacionais, as regras da internacionalização continuam, ainda, no mundo de hoje, sendo ditadas pelos países mais fortes e as regras da economia pelo grupo dos sete, hermético e superior, que discute e impõe, na decorrência, a política mais adequada para todo o mundo, em sua especial visão, como se fossem seus integrantes os senhores do tempo e da história.

À evidência, houve evolução em determinados mecanismos de proteção dos países mais fragilizados, sendo a OPEP, no passado até a guerra fraticida dentre os árabes, e o Mercosul, no presente, enquanto os interesses menores dos argentinos não puserem em risco o Tratado de Assunção, provas de que se poderiam ser criados grupos nacionais de pressão sobre a política impositiva dos países desenvolvidos. A defesa intransigente do Mercosul pelo Presidente da República Fernando Henrique, contra a pressão

IV. não intervenção;

V. igualdade entre os Estados;

VI. defesa da paz;

VII. solução pacífica dos conflitos;

VIII. ' repúdio ao terrorismo e ao racismo;

IX. cooperação entre os povos para o progresso da humanidade;

X. concessão de asilo político.

$\S$ único. A República Federativa do Brasil buscará a integração econômica, política, social e cultural dos povos da América Latina, visando à formação de uma comunidade latino-americana de nações".

Apesar da nobreza de princípios, o Brasil tem pouca força para fazê-los respeitados.

${ }^{5}$ Roberto Campos inclusive justifica as atitudes americanas, pela inquietação de seu povo ao dizer: "E não sem razão. A maioria dos americanos está cansada de pagar cada vez mais (só nạ década de 80 , os gastos de estados e municipalidades mais do que dobraram) por conta de novas obrigaçóes provenientes das coceiras eleitorais e da covardia dos políticos diante de interesses especiais estridentes. Segundo pesquisas de opinião, os americanos acham que o governo se tornou tão poderoso, que constitui uma ameaça para os direitos e as franquias dos cidadãos. Em 92, o candidato à presidência, Ross Perot, um milionário excêntrico sem papas na língua, chegou a ter 35\% da preferência dos votos. E muito recentemente, em 1955, 58\% do público apoiaria um "terceiro partido", isto é, nem democrata, nem republicano. E também os índices de satisfação do público (aliás, não só nos Estados Unidos como em vários países europeus e no Japão), há meio século não aumentam, apesar do enorme crescimento da renda per capita. Ou seja, a afluência acrescida gera demandas adicionais, mas persiste um descontentamento difuso com a estreitezza do espaço humano individual". (O Estado do Futuro, Ed. Pioneira, 1998, p. 31).

${ }^{6}$ D'Ors sobre o "jus gentium" que decorre do "jus civile" escreve:

“§ 32. Los romanos tuvieron justa conciencia de la superioridad de su ius civile. Puede decirse, en efecto, que éste es el derecho "civilizado" po excelencia. pero en él hay instituciones que se consideran como de validez general para todos los pueblos relacionados com Roma, porque se fundan, más que en la forma, en el principio de lealtad a la palabra dada, es decir, la fides. La fides es una idea central del pensamiento jurídico y político de Roma: propiamente, la lealtat a la palabra dada. Es una virtud del más poderoso; así, la fides deorum (cfr. la exclamación “"'ro deum fidem!") es la proteccion que dispensan los dioses, y la fides romana por excelencia es la firmeza de Roma respecto a seus aliados (de donde foedus, alianza); asimismo hay una fides patroni respecto a los propios clientes (§ 21), una "fides tutoris, iudicis", etc. La "fides" llega donde no alcanza la fuerza 
americana para destrui-lo e substitui-lo pela ALCA, é que permitiu que os americanos recuassem na sua intransigência e aceitassem discutir com o bloco e não com cada nação individual a formatação da Associação de Livre Comércio Americano. É de se lembrar que, na formação de espaços comunitários, permite-se o livre trânsito de bens e pessoas, tese que a preconceituosa visão dos estados Unidos não admite, ao ponto de, no NAFTA, os mexicanos não poderem livremente entrar e sair dos Estados Unidos ou se estabelecer no espaço comunitário (Canadá e Estados Unidos), pois aos americanos apenas interessa o livre trânsito de bens, onde sua competitividade é maior do que a de canadenses e mexicanos.

Mesmo o Canadá, na busca de mercados próprios, obteve da $\mathrm{OMC}$, entidade a serviço da competitividade dos países desenvolvidos, que a equalização de juros no mercado internacional pelo "Proex" fosse considerada inaceitável para o mercado externo, de tal maneira que os aviões canadenses podem ser financiados a juros de nível internacional, mas os aviões brasileiros só podem ser financiados a juros de mercado brasileiro, ou seja, algumas vezes maiores que os juros internacionais. Desta maneira, a competitividade, que estaria em poderem, canadenses e brasileiros, utilizar-se do mesmo nível de juros ou financiamento, na visão estrita e aristocrática dos "donos" da OMC não é assim. Apenas os canadenses podem se beneficiar de juros internacionais, pois os brasileiros só podem ser financia- dos pelos juros mais elevados do Brasil!!!!?

Tais considerações eu as trago para a reflexão, neste breve artigo para levantar a questão que me tem preocupado.

De um lado, a título de defesa de direitos fundamentais, a garantia dos direitos políticos de autoridades de nações menos desenvolvidas não é reconhecida nos países desenvolvidos, como é o caso de Pinochet que, sendo Senador e membro do poder Legislativo chileno, foi preso na Inglaterra, para ser julgado na Espanha, por crimes cometidos no Chile, sua pátria.

Fidel Castro, que conta na sua bagagem com crimes muito mais hediondos que os de Pinochet, sobre ter assassinado um número maior de pessoas, só não é atingido nesta visão elitista, por ser de esquerda e o "lobby" esquerdista, mesmo nos países mais desenvolvidos, é indiscutivelmente muito superior que o da direita. Por isto pode Fidel Castro viajar tranqüilo, com sua bagagem imensa de violação de direitos fundamentais, pelos países desenvolvidos, por contar com a proteção da mídia, embora, a meu ver, tanto Fidel Castro quanto Pinochet deveriam ser julgados por Tribunais Internacionais, por terem praticado crimes contra a humanidade.

No caso, entretanto, não é a minha posição, nitidamente contrária à violação dos direitos fundamentais, que está no cerne deste artigo, mas a preocupação de que, sob o verniz da defesa dos direitos fundamentais, os países mais desenvolvidos sintam-se no direito de violar a

vinculante de la forma, y es el fundamento de todas las obrigaciones no-formales, por ej., el préstamo mutuo ("fidem sequi credere"). Distinta es la "bona fides", que se refiere a la lealtad recíproca de las dos partes de un contrato (§ 452), y de ahí quizá (através de la "bona fides" del comprador) se aplica el concepto a la posesión sin conocimiento de perjudicar un mejor derecho (§ 147)”. (Derecho Privado Romano, Ed. EUNSA, Pamplona, 1983, p.62).

'A Embraer contînua debatendo na $\mathrm{OMC}$ o seu direito de ter juros idênticos aos da Bombardier, sendo pois o Proex não um incentivo, mas um programa de equalização.

${ }^{8}$ Escrevi: "Em 1ํ de outubro de 1946, o tribunal de Nuremberg julgou 22 nazistas criminosos de guerra, à luz, exclusivamente, de princípios de direito natural, considerando-os, com exceção de 3 deles, culpados de crimes contra a humanidade. A defesa de que teriam apenas cumprido as leis de seu país e que, em uma visão positivista do direito, não poderiam ser condenados, não foi acatada, pois decidiu a Corte que há princípios de direito natural que se sobrepõem aos do direito posto, se contrários à dignidade e à honra humana.

Dois anos depois, em 10 de dezembro de 1948, a Organização das Nações Unidas promulgou sua declaração universal de direitos, tornando obrigatório, para os países signatários de sua formulação, hospedarem, em seus ordenamentos internos, aqueles 
soberania dos países menos desenvolvidos.

Indiscutivelmente, a "purificação étnica" dos albaneses é ignominiosa. A decisão, todavia, de intervenção militar, não foi uma decisão da comunidade internacional, mas dos países mais desenvolvidos, sem respeito à soberania da Iugoslávia. Embora plenamente justificável a defesa dos albaneses, o método utilizado e a decisão elitista que o conformou, arranha o direito internacional e o princípio da soberania das nações.

Ora, minha preocupação reside no precedente aberto, que poderá levar, um dia, também sob o verniz dos direitos universais, os países mais desenvolvidos a entender, por exemplo, que, para a preservação da população indígena ou do meio ambiente da Amazônia, ambos com tratamento constitucional (artigos 225,231,232), a Amazônia deva ser considerada território universal e não mais brasileiro, decidindo, a título de proteger os índios e a floresta amazônica, intervir no Brasil. ${ }^{9}$

Inúmeras vezes, em todos os anos, o tema floresta amazônica e população indígena é abordado, na mídia e em seminários internacionais, sendo recorrente a conclusão de que o Brasil pre- cisa preservar a floresta amazônica para o bem da humanidade. Tal repetitivo tema não torna desarrazoado o temor que manifesto, neste artigo, principalmente quando tais seminários - e participei de um deles, na Alemanha, em 1991 cuidam da Amazônia como se já fosse parte do "ambiente universal" a ser preservado pelos mais fortes. Eles, que não souberam preservar suas florestas, querem que preservemos para eles nossa floresta. Não titubearam em sacrificar o meioambiente para crescer e se desenvolver. Agora, é necessário, para o bem-estar deles, que nós não cresçamos e nem nos desenvolvamos no espaço amazônico.

Em outras palavras, os procedimentos que começam a ser abertos na década de 90 , sobre os limites da soberania das nações, reduzindo-os a uma concepção internacional que só permite a plena soberania aos países desenvolvidos, é algo que me preocupa, pois, a título de seus nobres ideais, verdadeiros atentados à soberania das nações emergentes podem ser perpetrados, sem que estas tenham um "foro" internacional a que apelar. $^{10}$

É matéria que merece reflexão.

princípios que recolocavam, à luz do direito, o homem em sua dignidade transcendental, que adquire desde o nascimento. René Cassin, jusnaturalista e um dos autores da carta de 1948, assim explicava a origem da Declaração: "não é porque as características físicas do homem mudaram pouco, desde o começo dos tempos verificáveis, que a lista de seus direitos fundamentais e liberdades foi idealizada para ser fixada permanentemente, mas em função da crença de que tais direitos e liberdades lhe são naturais e inatos" (Human Rights since 1945: A Appraisal, The Great Ideas, 1971, Ed. Britannica, p. 5). Comemoramse, em 10 de dezembro, os 50 anos daquele histórico documento. Muitos dos países que compóem o concerto das Nações Unidas não respeitam tais direitos, nem os hospedam no seu direito interno, principalmente as ditaduras de Hussein, Fidel e a da China, onde o desrespeito aos direitos humanos é inequívoco, com condenações à morte sem julgamento. De triste memória, são os "paredons" de Cuba para justificar fuzilamentos sem direito de defesa das pessoas contrárias ao ditador Castro. O certo, todavia, é que a declaração universal representou considerável avanço na compreensão das nações de que todo o ser humano nasce com uma dignidade própria, que não cabe ao direito de cada país criar ou não, mas apenas reconhecer". (Direitos Individuais, Iñterprensa, ano II., nº 20, Dez/1998, p.4).

${ }^{\circ} \mathrm{O}$ "caput" do artigo 225 está assim redigido: "Todos têm direito ao meio ambiente ecologicamente equilibrado, bem de uso comum do povo e essencial à sadia qualidade de vida, impondo-se ao poder público e à coletividade o dever de defendê-lo e preservá-lo para as presentes e futuras gerações".

${ }^{10} \mathrm{O}$ "caput" do artigo 231 da Constituição Federal está assim redigido: "São reconhecidos aos índios sua organização social, costumes, línguas, crenças e tradições e os direitos originários sobre as terras que tradicionalmente ocupam, competindo à União demarcá-las, proteger e fazer respeitar todos os seus bens". 